\title{
Interactions Between Hematopoietic Growth Factors: The Clinical Role of Combination Biotherapy*
}

M.A.S. Moore

\section{A. Introduction}

The Frederick Stohlman Memorial Lectures have, over the years, reflected the progression of leukemia research in areas initially thought to be as diverse as retrovirology/oncogenes, chemotherapy/immunotherapy, and hematopoietic growth factors. At the Seventh Wilsede Meeting we heard how convergent these areas were. The polypeptide growth factors which affect lymphohematopoietic cell proliferation and differentiation have expanded to at least 11 distinct gene products with pleiotropic and overlapping functions (G-, GM-, M-CSF, erythropoietin, and interleukins 1-7 [1]. The early characterization of hematopoietic growth factors was based on their ability to stimulate the clonal proliferation of human bone marrow progenitor cells. In addition, these factors were shown to activate a variety of functions of mature lymphoid and hematopoietic cells.

The purification, characterization, and gene cloning of human G-CSF followed shortly after the equivalent characterization of human GM-CSF $[2,3]$. With the availability of recombinant G-CSF in quantities sufficient for in vivo evaluation, its action on hematopoietic function was assessed in normal murine and primate systems, and following chemotherapy or radiation-induced myelosup-

The James Ewing Laboratory of Developmental Hematopoiesis, Memorial Sloan-Kettering Cancer Center, New York, NY 10021, USA

* Supported by grants CA 20194, CA 32156, and CA 31780 from the National Cancer Institute; American Cancer Society Grant CH-3K, and the Gar Reichman Foundation. pression [1, 4, 5]. Efficacy was rapidly demonstrated and opened the way to clinical trials in human bone marrow suppression or failure systems [6-8]. Without reviewing this area in detail, I wish to touch on various aspects that illustrate the utility of G-CSF in various pathophysiological situations.

\section{B. Hematopoietic Role of G-CSF}

\section{G-CSF Treatment of Mice}

Receiving Cyclophosphamide, Myleran, or 5-Fluorouracil

In order to investigate the potential of G-CSF in preventing episodes of neutropenia following high-dose chemotherapy with cyclophosphamide $(\mathrm{CY}), \mathrm{C} 3 \mathrm{H} /$ $\mathrm{HeJ}$ mice were subject to weekly injections of $200 \mathrm{mg} / \mathrm{kg} \mathrm{CY}$ intraperitoneally followed by G-CSF therapy $(1.75 \mathrm{~g} \times 2$ daily) beginning $2 \mathrm{~h}$ after $\mathrm{CY}$ treatment and finished $48 \mathrm{~h}$ before the second cycle of CY. As shown in Fig. 1, this protocol prevented the subsequent nadirs of neutrophil counts between 4 and 5 days after CY treatment, and in all ten cycles of CY therapy G-CSF abrogated the neutrophil nadirs. The mice receiving $\mathrm{CY}$ alone had a substantial mortality evident by the eighth cycle of treatment. In eight cycles of CY treatment over the course of 70 days the G-CSF-treated animals were neutropenic $\left(1000 \mathrm{ANC} / \mathrm{mm}^{3}\right)$ for only 3 days, whereas the untreated animals were neutropenic for 24 days. The time to recovery of absolute neutrophil counts (ANCs) to control levels was also substantially affected, with the non-G-CSFtreated groups requiring an additional 16 days for recovery. Neutropenia at levels 


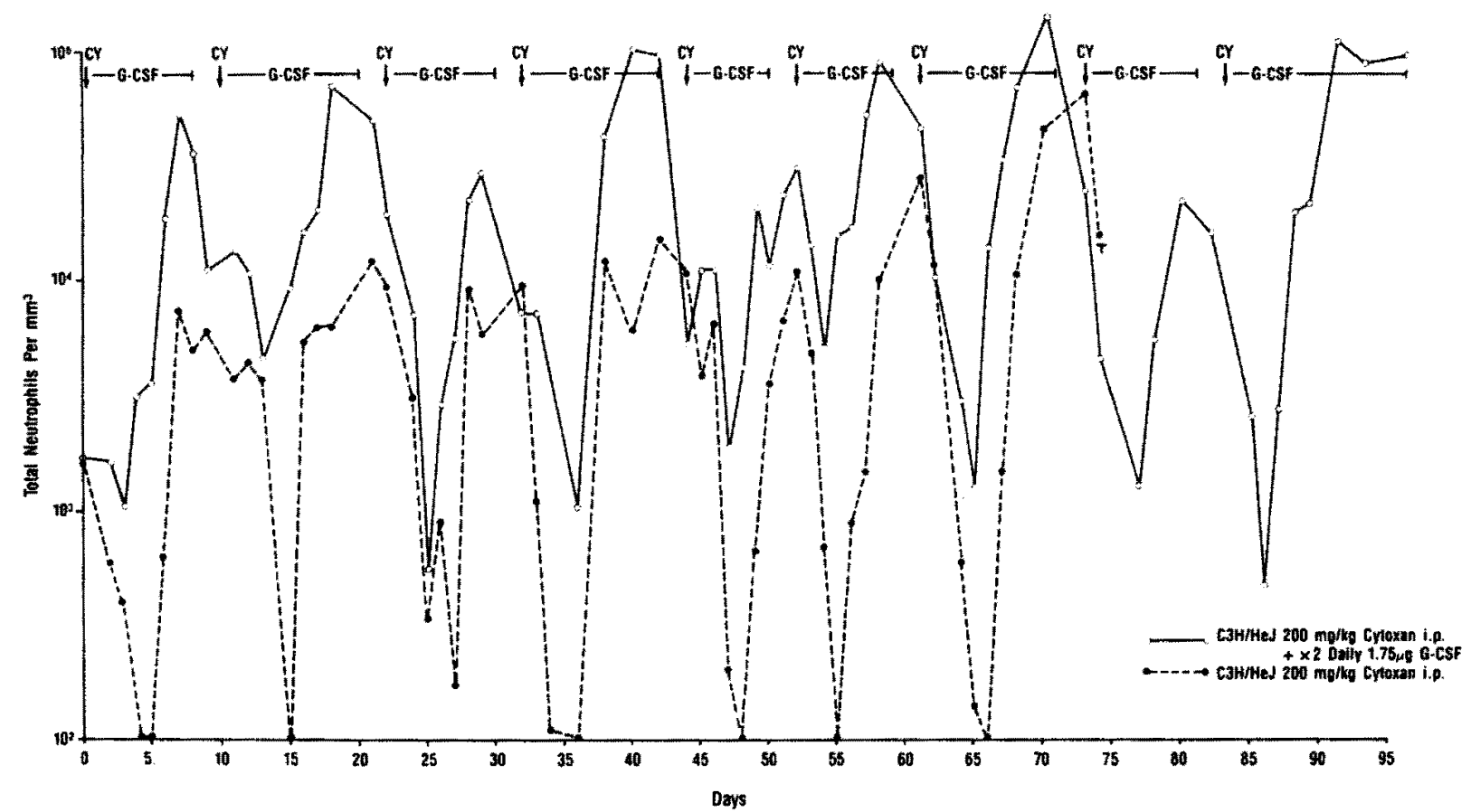

Fig. 1. Absolute neutrophil counts in the peripheral blood of $\mathrm{C} 3 \mathrm{H} / \mathrm{HeJ}$ mice treated with repeated dosed of $200 \mathrm{mg} / \mathrm{kg}$ cyclophosphamide (CY) administered at 7- to 9-day intervals over 3 months. Control mice (broken line) received saline alone; experimental mice (continuous line) received $1.75 \mathrm{mg}$ rhG-CSF twice daily intraperitoneally beginning $2 \mathrm{~h}$ following $\mathrm{CY}$ and terminating $48 \mathrm{~h}$ prior to the next cycle of CY. Three mice per group. Note the log scale for $\mathrm{ANC} / \mathrm{mm}^{3}$

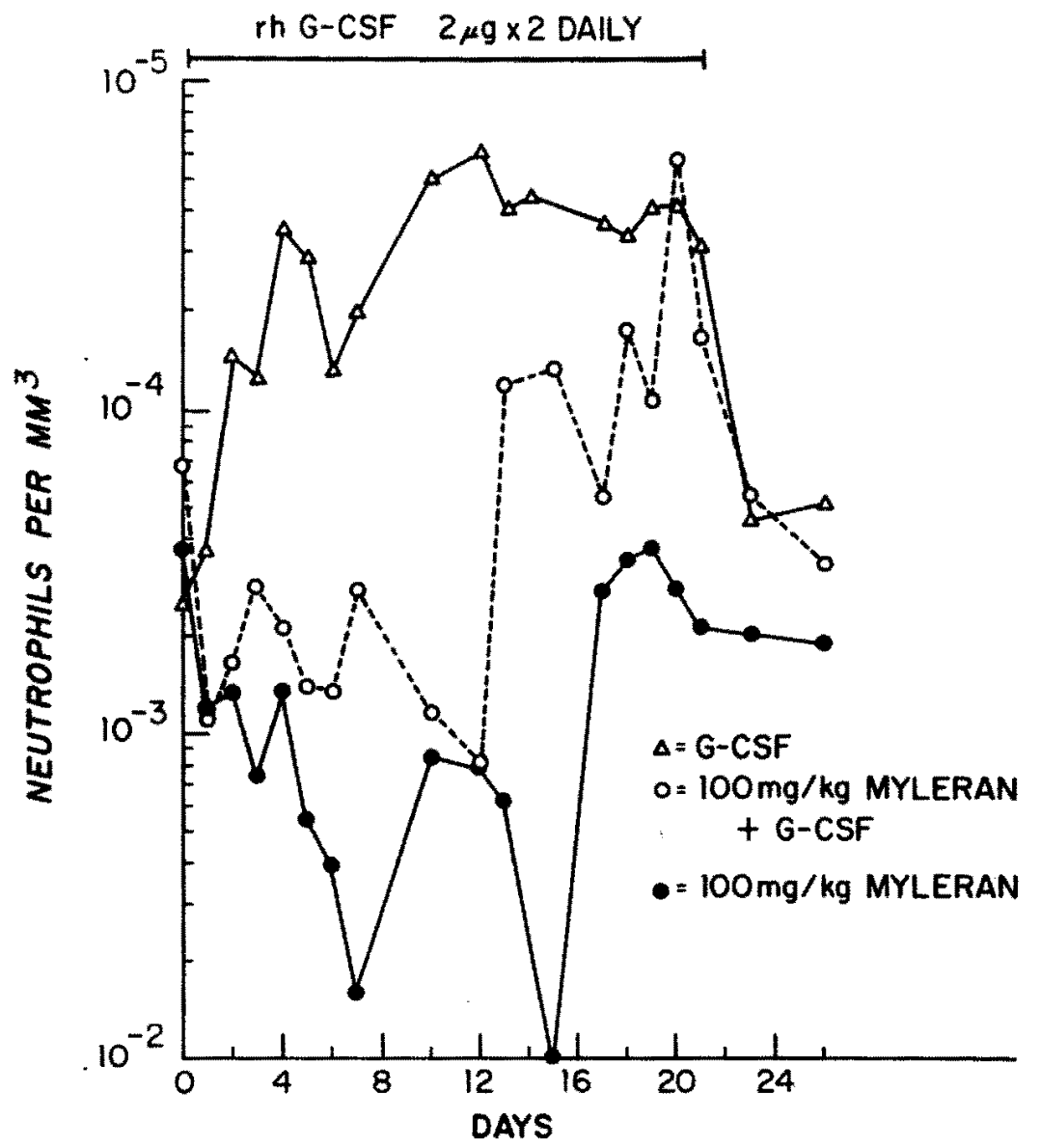

Fig. 2. Absolute neutrophil counts in the peripheral blood of $\mathrm{C} 3 \mathrm{H} / \mathrm{HeJ}$ mice administered $100 \mathrm{mg} / \mathrm{kg}$ myleran orally by intubation with or without twice daily i.p. injections of rh-G-CSF at $2 \mu \mathrm{g} /$ mouse for 21 days. Control animals received corn oil alone with G-CSF. Four mice per group. Note the log scale 
of $500 \mathrm{ANC} / \mathrm{mm}^{3}$ indicated an even more significant difference, with such low levels observed on only 1 day out of 70 in the G-CSF + CY-treated mice, in contrast to 15 days in the CY-treated group.

This cyclophosphamide model allowed us to investigate the timing of initiation of G-CSF therapy following a single injection of a high dose of CY. Administration of G-CSF coincident with CY treatment resulted in an improvement in recovery of neutrophil counts, but this was substantially less than observed when GCSF was administered $2 \mathrm{~h}$ after $\mathrm{CY}$ therapy. Administration of G-CSF 24 and $48 \mathrm{~h}$ after $\mathrm{CY}$ was less effective than after $2 \mathrm{~h}$, indicating that treatment early in the course of chemotherapy is likely to be more effective.

Myleran (MY), administered orally $(100 \mathrm{mg} / \mathrm{kg})$, was also associated with a significant reduction in neutrophil counts and in bone marrow progenitor populations. G-CSF therapy initiated within $6 \mathrm{~h}$ of MY treatment led to an accelerated recovery of neutrophils so that by 1 week the neutrophil counts had returned to normal values, whereas the MY-treated controls remained profoundly neutropenic (ANC $200 / \mathrm{mm}^{3}$ ) (Fig. 2). By 14 days MY + G-CSF-treated animals exhibited a neutrophil leukocytosis of between $10^{4}$ and $2 \times 10^{4} / \mathrm{mm}^{3}$ at times when the MY control animals had 100 neutrophils $/ \mathrm{mm}^{3}$.

Treatment with 5-fluorouracil (5-FU $150 \mathrm{mg} / \mathrm{kg}$ ) led to profound myelosuppression in three different strains of mice tested. In $\mathrm{C} 3 \mathrm{H} / \mathrm{HeJ}$ mice, recovery of neutrophil counts to control values was delayed for 12-14 days. Administration of G-CSF accelerated recovery of neutrophil counts to normal values within 8 days [5].

\section{Clinical Trials of G-CSF Following Chemotherapy}

The use of rh-G-CSF in clinical trials has demonstrated efficacy in promoting regeneration of functioning neutrophil granulocytes. Our first clinical trial involved the administration of G-CSF in a phase I/II study of patients receiving MVAC (methotrexate, vinblastine, doxarubicin, and cisplatin) in 22 patients with transitional cell carcinoma of the uroepithelium [6]. In all patients a specific dose-dependent increase in ANC was seen to levels of up to 12-fold above normal at the higher levels of G-CSF administration. At these high doses $(10-60 \mathrm{~g} /$ $\mathrm{kg}$ ) a tenfold increase in monocytes, but not in other hematopoietic lineages, was evident. Treatment after chemotherapy significantly reduced the number of days on which antibiotics were used. This resulted in a significant increase in the number of patients qualified to receive planned chemotherapy on day 14 of the treatment cycle $(100 \%$ vs. $29 \%)$. In addition, the incidence of mucositis significantly decreased. Investigators at other centers have confirmed these observations. In patients with advanced small cell lung cancer receiving high-dose chemotherapy, repeated every 3 weeks, G-CSF was given to each patient for 14 days on alternate cycles of chemotherapy. This resulted in the reduction of the period of absolute neutropenia with return to normal or supranormal levels of ANC within 2 weeks [8]. This therapy also drastically reduced episodes of severe infections observed during these cycles of chemotherapy. In advanced malignancies treated with melphalan, neutropenia was significantly reduced even at dose levels of 1 or $3 \mu \mathrm{g} / \mathrm{kg}$ G-CSF. Preliminary clinical studies have also demonstrated that G-CSF hastens granulocyte recovery in Hodgkin's disease after high-dose chemotherapy and autologous bone marrow transplantation [9]. In all of these studies no significant dose-limiting toxicities have been observed to date.

III. In Vivo Studies of G-CSF in Congenital and Idiopathic Neutropenia

Cyclic neutropenia is an inherited disease of man and gray collie dogs, character- 
ized by regular oscillations of the number of peripheral blood cells and of bone marrow progenitor cells. Cycling of serum or urine CSF levels has also been reported. However, induction or cure of cyclic neutropenia by bone marrow transplantation has suggested that this disorder is a disease of pluripotential hematopoietic stem cells. It should be noted that the hematopoietic stem cell itself can generate cells (macrophages, $\mathrm{T}$ cells) capable of hematopoietic growth factor production and thus it is not possible to exclude intrinsic growth factor production defects in the pathophysiology of cyclic neutropenia. In the dog model we have demonstrated that daily administration of rh-G-CSF $(5 \mu \mathrm{g} / \mathrm{kg} \times 2$ daily for 30 days) caused an immediate (within $12 \mathrm{~h}$ ) and persistent leukocytosis $(>40000 \mathrm{WBC})$ in both cyclic and normal dogs due to a ten fold increase in the numbers of circulating neutrophils and monocytes [10]. This therapy eliminated two predicted neutropenic episodes and suppressed the cycling of CFU-GM in the bone marrow. Comparable therapy with rh-GM-CSF induces a monocytosis and neutrophilia in normal dogs but did not eliminate the recurrent neutropenia in cyclic dogs. Analysis of the serum levels of CSF indicated a striking periodicity with peak levels of G-CSF coinciding with the peaks of monocytes and the nadirs of neutrophils. The continuing cycling of CSF levels was also observed even when animals showed a major neutrophil leukocytosis under exogenous GCSF therapy.

A disorder of neutrophil regulation is also seen in chronic idiopathic neutropenia in which the peripheral neutrophil count is reduced to 2000 cells $/ \mathrm{mm}^{3}$ for prolonged periods, with maturation arrest of neutrophil granulocyte precursors in the bone marrow. Other hematopoietic cell counts are usually normal and antineutrophil antibodies are absent. Clinically, these patients experience recurrent episodes of life-threatening infections, ulcers of the mucus membrane, and periodontal disease. We have had the oppor- tunity of studying a number of patients with this disorder utilizing primary clonogenic assay and in vitro suspension cultures of patient bone marrow cells [7]. The incidence of CFU-GM observed in primary bone marrow culture was always in the high range of normal with respect to each species of CSF (G-, GM-, M-, and IL-3), indicating that the neutropenia was not attributed to a shortage of appropriate myeloid progenitors. Furthermore, morphological studies showed normal neutrophil maturation within the colonies developing in the presence of G-, GM-CSF, and IL-3, with eosinophil maturation and macrophage development a significant feature with GM-CSF stimulation. In suspension cultures GCSF was particularly effective in generating mature segmented neutrophils which were absent in input bone marrow, and did not develop spontaneously in over 3 weeks of culture. With the addition of G-CSF, myelocytes expanded in the 1st week of culture. By the 2nd and 3rd week high levels of production of segmented, functionally normal neutrophils were found. Based upon these in vitro studies, patients were treated with subcutaneous G-CSF on a daily continuous basis. In the first patient studied, the neutrophil count rose rapidly, and by 20 days the patient's ANC was $>1000$ cells $/ \mathrm{mm}^{3}$ and plateaued in the range of 2000 $3000 / \mathrm{mm}^{3}$ with evidence of a 40-day cycle (observed even when the dose of G-CSF was increased). The neutrophils were functionally normal and the patient has remained on this continuous G-CSF treatment without any notable toxic side effects [7].

A more severe form of neutropenia is found in patients with Kostmann's syndrome (congenital agranulocytosis). In this disorder, marked by severe neutropenia and maturation arrest at the myelocyte level, five patients received GCSF therapy, and the neutrophils increased from $0 \%-1 \%$ to $10 \%-72 \%$ with clinical resolution of preexisting infections [11]. 


\section{Hematopoietic Role of Interleukin-1}

Interleukin-1 (IL-1) was first identified as an endogenous pyrogen, produced by macrophages following activation by endotoxin. Subsequent studies implicated IL-1 as a mediator of a variety of inflammatory phenomena involving production of cascades of cytokines and cyclooxagenase products [12]. Various lymphokines are released by the interaction of IL-1 with T cells, and IL-1 induces expression of G-, GM-, and MCSF by a direct action on stromal cells such as fibroblasts and endothelial cells, both in vitro and in vivo [13-15]. Recent studies have revealed a more direct role for IL-1 in hematopoiesis, involving an interaction with the early hematopoietic stem cell $[5,16-18]$.

I. Interleukin-1 Identity with Hemopoietin 1/Synergistic Activity

Early studies involving mice treated with 5-fluorouracil (5-FU) suggested the necessity of a synergistic interaction between two factors, one being a direct hematopoietic colony stimulus such as $\mathrm{M}$ CSF or IL-3, and the other, which lacked direct colony-stimulating activity, was shown to synergize with the preceding species of CSFs [19]. Synergistic activity was identified in conditioned media or extracts of various human tissues and was also identified and purified to homogeneity from the human bladder cancer cell line, 5637 [20]. This latter cell line had also been used to identify, purify, and clone G- and GM-CSF [2, 3, 21]. The constitutive expression of hemopoietin 1 (H-1), which was shown to be a $17000-$ kd protein [20], led us to attempt to purify, sequence, and clone this molecule, using similar strategies to those that we had employed to clone the G-CSF gene from 5637 cells. The identity of IL-1 and H-1/ synergistic activity was established on the basis of the following factors:

1. The bladder cancer cells evidently produced high levels of IL-1 active in the thymocyte comitogenesis assay.
2. The synergistic activity and IL-1 could be copurified using various protein purification procedures.

3. Abundant levels of IL-1-alpha and -beta mRNA could be detected in the 5637 cells - comparable to levels in activated macrophages.

4. Fractions of in RNA from 5637 expressed in oocytes resulted in intracellular production of hematopoietic synergistic activity and thymocyte comitogenesis factor production.

5. The synergistic activity and thymocyte comitogenesis activity were completely neutralized by monoclonal and polyclonal antibodies to IL-1.

6. rhIL-1 alpha and beta at $0.1-10 \mathrm{U} / \mathrm{ml}$ synergized with G-, GM- M-CSF, and IL-3 in stimulating high proliferative potential (HPP)-CFU in clonogenic assays of 5-FU-treated murine bone marrow $[1,5,16-18]$.

IL-1 has a direct effect upon hematopoietic stem cells in addition to its ability to elicit production of various CSF species by accessory cell populations within hematopoietic tissues. In our original studies it was not possible to conclude that IL-1 was acting directly on early stem cells since accessory cell populations were not depleted from the target bone marrow cell population. In more recent studies we have established a linear doseresponse relationship between the numbers of HPP-CFU, and the number of bone marrow cells plated, with a highly significant correlation $(r=0.97)$ indicative of a single-hit phenomenon.

\section{Action of IL-1 in Short-term Marrow Suspension Culture (Delta Assay)}

The rationale behind the delta assay is to demonstrate the ability of hematopoietic growth factors to promote the survival, recruitment, or expansion of stem cells and/or progenitor cells in relatively shortterm suspension culture systems. As originally developed, we utilized bone marrow from mice that had been treated with 5-FU for $24 \mathrm{~h}$ and then subjected to a 4- to 7-day suspension culture in the 
Table 1. Interleukin-1 and CSF-induced amplification of CFU-GM in 7-day suspension cultures of $2.5 \times 10^{5}$ murine bone marrow cells obtained $24 \mathrm{~h}$ post 5 -fluorouracil treatment

\begin{tabular}{lcccc}
\hline $\begin{array}{l}\text { Stimulus in suspension } \\
\text { phase }\end{array}$ & \multicolumn{4}{l}{ Delta (CFU-GM output/input) } \\
\cline { 2 - 5 } & \multicolumn{2}{l}{ "Readout" stimulus in $2^{\circ}$ clonogenic assay } \\
\cline { 2 - 5 } & G+IL-1 & GM+IL-1 & IL-3 + IL-1 & CSF-1 + IL-1 \\
\hline Medium & 0 & 0 & 0 & 0 \\
rh-IL-1 alpha & 190 & 53 & 39 & 61 \\
rh-G-CSF & 0 & 5 & 2 & 5 \\
IL-1 + G-CSF & 255 & 91 & 41 & 41 \\
mCSF-1 & 0 & 2 & 1 & 2 \\
IL-1 + CSF-1 & 175 & 47 & 38 & 80 \\
mGM-CSF & 40 & 17 & 15 & 34 \\
IL-1 + GM-CSF & 280 & 58 & 49 & 54 \\
mIL-3 & 110 & 17 & 18 & 33 \\
IL-1 + IL-3 & 510 & 178 & 120 & 115 \\
\hline
\end{tabular}

Femoral bone marrow cells taken from B6D2F1 mice $24 \mathrm{~h}$ after a single i.v. injection of 5 -fluorouracil $(150 \mathrm{mg} / \mathrm{kg})$ were incubated at $2.5 \times 10^{5}$ cells $/ \mathrm{ml}$ in Iscove's modified Dulbecco's medium with $20 \%$ fetal calf serum in 24-well cluster plates containing 100 units rh-IL-1 alpha, or $2000 \mathrm{u} / \mathrm{ml} \mathrm{rh}-\mathrm{G}-\mathrm{CSF} ; 1000 \mathrm{u} / \mathrm{ml}$. m-GM-CSF (purified from murine post-endotoxin lung CM) $200 \mathrm{u}$ m-IL-3 (purified from WEHI-3 cell line CM), or $1000 \mathrm{u}$ CSF-1 (purified from L-cell $\mathrm{CM}$ ). After 7 days of incubation, cells were recovered and assayed for CFU-GM in agarose cultures stimulated by the various CSF species alone or in combination with IL-1. The delta value (CFU-GM output/input) was calculated on a recovery from triplicate clonal assays from triplicate suspension cultures

presence of IL-1 alone, CSFs alone, or combinations of IL-1 with various CSF species $[5,16]$. At the end of the suspension culture phase, total cellularity and morphology was determined, and cells were cloned in semisolid culture, again in the presence of IL-1 alone, CSFs alone, or combinations of IL-1 and CSFs. Table 1 shows that IL-1 caused an expansion of the numbers of CFU-GM recovered after 7 days of culture. Neither M-CSF nor G-CSF alone supported survival or expansion of CFU-GM; however, the combination of IL-1 and CSFs demonstrated additive or synergistic effects on the expansion of these progenitors. GM-CSF or IL-3 alone caused some expansion of progenitor populations, but again the combination with IL-1 evidenced synergism.

Human systems based on in vitro purging with 4-hydroperoxcyclophosphamide $(4 \mathrm{HC})$ and positive selection by "panning" with MY10 monoclonal anti- body for CD $34^{+}$cells followed by 7-day suspension culture also demonstrated synergistic interactions between IL-1 and various CSF species. The most dramatic effect was observed with the combination of IL-1 and IL-3, where an up to 85-fold increase in progenitor cells was noted following 7-day suspension culture (Table 2). In contrast to the murine system, synergism between IL-1 and CSF-1 was not evident.

III. In Vivo Interaction Between IL-1 and G-CSF in Mice Treated with 5-FU

In mice trated with 5-FU, G-CSF administration restores neutrophil counts to normal values some 5-6 days earlier than in mice not receiving the factor, but a period of profound neutropenia is still observed [5]. Administration of IL-1 alone, giving postchemotherapy for 4 10 days twice daily at doses of $0.2 \mu \mathrm{g} /$ mouse per day, reduced the severity of 
Table 2. Interleukin-1 and CSF-induced amplification of CFU-GM in 7-day suspension cultures of $2.5 \times 10^{5} 4$-HC-treated, CD34 ${ }^{+}$human bone marrow cells

Stimulus in suspension phase
Delta (CFU-GM output/input)

"Readout" stimulus in $2^{\circ}$ clonogenic assay

rh-G-CSF rh-GM-CSF rh-IL-3 rh-CSF-1

\begin{tabular}{lrrrr}
\hline Medium & 0 & 0 & 0 & 0 \\
rh-IL-1 alpha & 10 & 6 & 2 & 2 \\
rh-G-CSF & 8 & 9 & 2 & 2 \\
IL-1 + G-CSF & 8 & 9 & 2 & 1 \\
rh-GM-CSF & 8 & 9 & 2 & 2 \\
IL-1 + GM-CSF & 33 & 22 & 6 & 10 \\
rh IL-3 & 5 & 30 & 17 & 2 \\
IL-1 + IL-3 & 15 & 85 & 15 & 1 \\
\hline
\end{tabular}

Bone marrow cells, obtained with informed consent from normal volunteers, were separated over Ficoll-Hypaque, subjected to plastic adherence, and incubated for 30 min with $100 \mu M$ 4-hydroperoxycyclophosphamide (4-HC). Cells were then treated with antimyl monoclonal antibody (anti-HPCA-1 Beckon Dickinson, Mountain View Ca.), on ice for $45 \mathrm{~min}$, washed, and incubated for $1 \mathrm{~h}$ at $4^{\circ} \mathrm{C}$ on bacteriological-grade plastic petri dishes previously coated with goat anti-mouse IgG. Adherent $\mathrm{CD} 34^{+}$cells were harvested by vigorous pipetting. $2.5 \times 10^{5}$ harvested cells/well were incubated in Iscove's modified Dulbecco's medium (IMDM) plus $20 \%$ fetal calf serum in 24-well cluster plates containing test stimuli. In suspension phase, stimuli were $10 \mathrm{ng} / \mathrm{ml}$ rh-G-CSF, rh-GM-CSF, rh-IL-3 (Amgen), rh CSF-1 (Cetus), and rh-IL-1 alpha (Roche). 4-HC purged, CD34 ${ }^{+}$marrow cells were plated at $2 \times 10^{4}$ cells $/ \mathrm{ml}$ in semisolid agarose culture in the presence of $10 \mathrm{ng} / \mathrm{ml} \mathrm{GM-CSF,} \mathrm{G-CSF,} \mathrm{CSF-1,} \mathrm{or} \mathrm{IL-3} \mathrm{alone} \mathrm{or} \mathrm{in} \mathrm{combination}$ with IL-1 both pre- and postsuspension culture. Colony formation was assessed after 12 days. The delta value (CFU-GM output/input) was calculated on recovery from triplicate clonal assays from duplicate suspension cultures

the neutrophil nadir, and accelerated the recovery of the neutrophil count to an extent greater than observed with G-CSF alone. The combination of G-CSF and IL-1 administered after 5-FU therapy also resulted in accelerated hematopoietic reconstitution, although the results were additive rather than synergistic [5]. Analysis of total hematopoietic cell reconstitution in \%-FU-treated mice also showed the efficacy of IL-1 therapy, or IL-1 plus G-CSF therapy, in accelerating total recovery of erythroid as well as granulocytic elements in the marrow, spleen, and blood.

The potential of combination biotherapy as an effective means of accelerating hemopoietic cell differentiation raises the issue of whether premature exhaustion of the stem cell and progenitor cell population may occur. Measurement of colony- forming units (CFU-s, CFU-c, BFU-e, CFU-GEMM, CFU-Meg) on an incidence basis proved to be misleading because of the redistribution of hematopoietic precursors in regenerating murine tissues. By quantitation of total numbers of these cell populations in marrow, spleen, blood, and other tissues, we demonstrated that there was an absolute increase in the recovery of all of these populations in 5-FU-treated mice exposed to both IL-1 alone and IL-1 plus G-CSF. The results indicate that the mechanism of action of these cytokines, both alone or in combination, is not simply mediated by accelerated differentiation, but involves an absolute expansion of the most primitive stem cell populations that can be measured, e.g., by the day 12 murine spleen colony (CFU-s) assay, or the high proliferative potential in 
vitro colony assay requiring IL-1 plus CSF as the read-out stimuli $[1,5,16]$. This is an important observation for extrapolation of these studies to clinical situations because it lays to rest some of the concerns that combination biotherapy may accelerate exhaustion of the stem cell compartment in patients receiving myeloablative therapy.

\section{Interleukin-1 and CSFs as Radio- protective Agents}

Interleukin-1 has been shown to mediate a radioprotective action when given to mice $20 \mathrm{~h}$ before what would otherwise be a lethal dose of irradiation [12, 15]. This radioprotective effect cannot be duplicated by preadministration of various CSF species. Using BALB/c mice which are particularly susceptible to irradiation, we observed that $0.2 \mu \mathrm{g}$ IL-1 given $20 \mathrm{~h}$ before 850 rads total body irradiation completely prevented what would otherwise be $100 \%$ mortality by 14 days, confirming earlier reports. However, we were able to show that administration of IL-1 or G-CSF after irradiation was also significantly radioprotective. While the mechanism of $\mathrm{IL}-1$ radio- protection remains controversial, our down observations suggest that one mechanism may involve accelerated recruitment of primitive $G_{0}$ stem cells into the cell cycle with expression of CSF receptors. The administration of 750 rads total body irradiation to BALB/c mice, which resulted in $80 \%$ mortality within 14 days, provided a model in which we could test the interactions of IL-1 and G-CSF in reconstitution of hematopoiesis and in radioprotection. Recovery of neutrophils to normal levels in irradiated mice was delayed for up to 3 weeks; G-CSF administration begun immediately after irradiation, and carried out for 3 weeks, accelerated recovery of neutrophils and total hematopoietic cells, so that normal levels were observed by 14 days [22]. IL-1 administration as a single dose prior to irradiation resulted in accelerated recovery of hematopoiesis. When administered daily postirradiation for 4 days, IL-1 reduced the nadir of blood neutrophils and produced a degree of recovery of hematopoietic function comparable to that seen with G-CSF administration (Fig. 3). A significant synergistic interaction was noted when G-CSF was combined with IL-1 postirradiation,

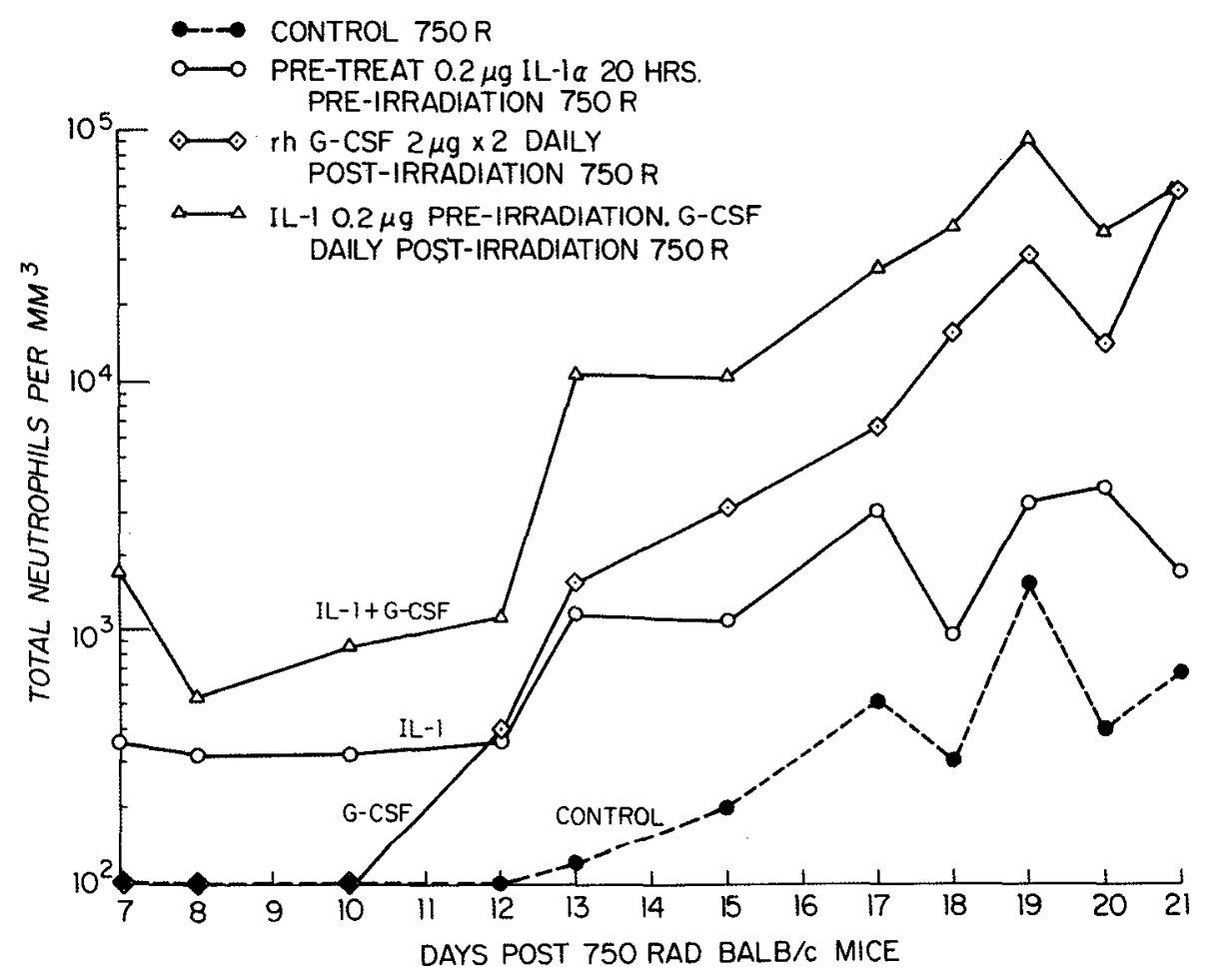

Fig. 3. Absolute neutrophil counts in the peripheral blood of Balb/c mice exposed to $750 \mathrm{rad}$ total body irradiation and either pretreated with rhIL-1 alpha $(0.2 \mu \mathrm{g} /$ mouse i. p. $20 \mathrm{~h}$ before irradiation) or treated with $2 \mu \mathrm{g}$ rh-G-CSF beginning $2 \mathrm{~h}$ postirradiation twice daily for 21 days, or the combination of IL-1 pre- and G-CSF post-treatment. Five mice per group. Control mice (broken line) received saline only 
Fig. 4. Absolute neutrophil counts in the peripheral blood of $\mathrm{B} 6 \mathrm{D} 2 \mathrm{~F} 1$ mice subject to 950 rads total irradiation and injected with varying numbers of syngeneic bone marrow cells, with or without subsequent twice daily administration of $2 \mu \mathrm{g}$ rhGCSF i.p. Five mice were used per group

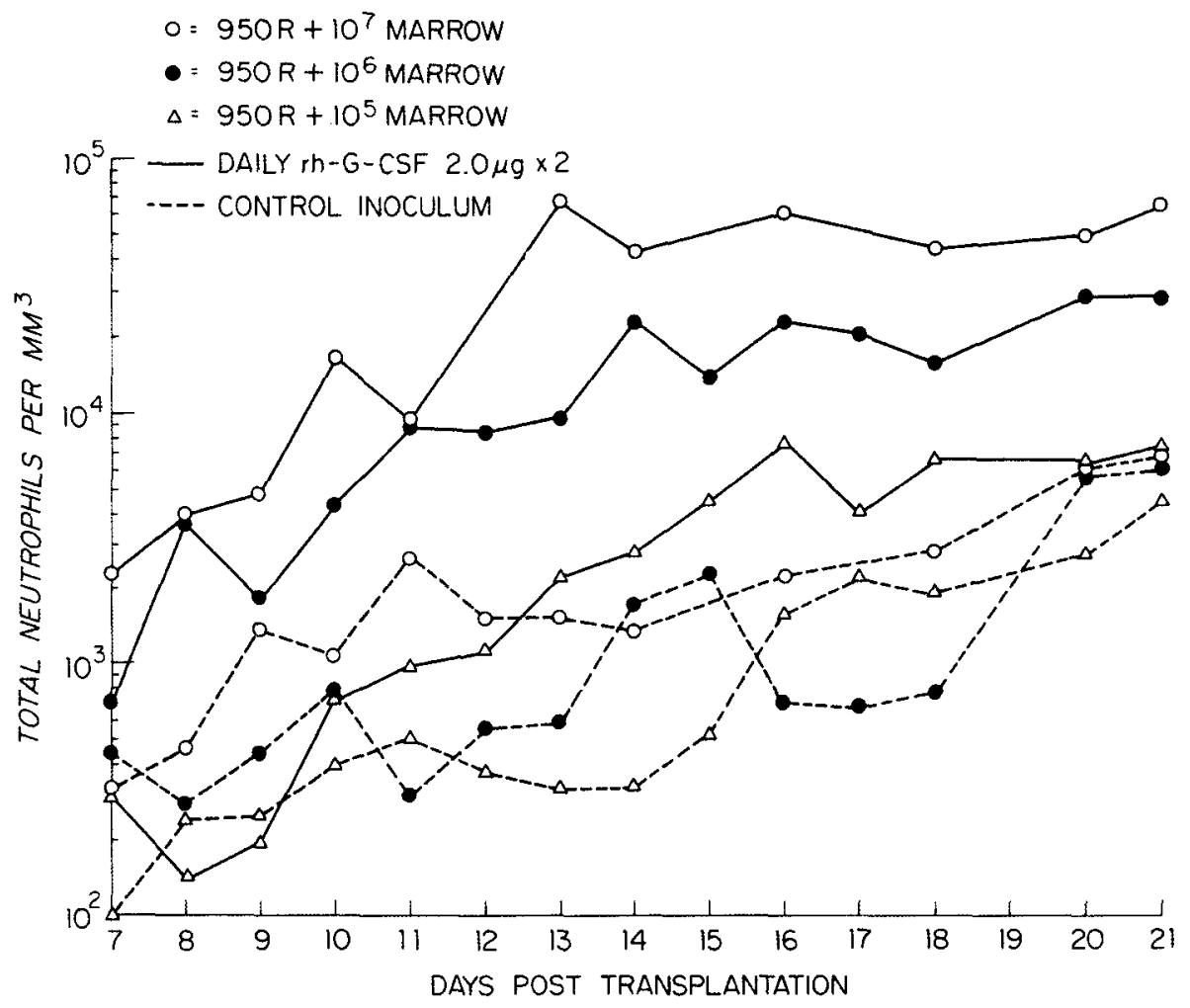

$0=950 R+10^{7}$ MARROW

950R + 106 MARROW

with up to a tenfold greater increase in blood neutrophils, hematopoietic cells, and both stem and progenitor cells populations in both spleen and bone marrow.

\section{Interactions Between IL-1 and G-CSF in Autologous Bone Marrow Transplantation}

Transplantation of autologous bone marrow into lethally irradiated $(950$ rads) $\mathrm{C} 3 \mathrm{H} / \mathrm{HeJ}$ and $\mathrm{B} 6 \mathrm{D} 2 \mathrm{~F} 1$ mice was undertaken using three different dose levels of donor marrow cells, $10^{5}, 10^{6}$, and $10^{7}$ cells/mouse. The $L^{2} D_{50}$ in such transplanted animals is observed at dose levels of 1.0-2.5 $\times 10^{6}$ marrow cells/ mouse. It is generally accepted that the delayed recovery in hematopoietic cells in the bone marrow and spleen and in peripheral neutrophil counts was attributed to limitations in the number of donor stem cells as measured by the CFU-s assay. As can be seen in Fig. 4, the peripheral neutrophil counts reflected a marrow cell dose-dependent difference in a return to normal values. While this observation (which was also reflected in bone marrow and spleen hematopoietic cell reconstitution) might lead to the assumption that stem cell availability is the sole criterion for hematopoietic reconstitution, the administration of exogenous G-CSF suggested additional variables in the transplant equation. In all instances following autologous bone marrow transplantation at the different dose levels, exogenous G-CSF administration enhanced the recovery of neutrophils in the peripheral blood by three- to tenfold. This in turn was accompanied by accelerated regeneration of bone marrow and spleen hematopoietic progenitor cells and of pluripotential stem cells as measured by the CFU-s assay.

Studies in autologous bone marrow transplantation in cynomolgus monkeys confirmed the ability of G-CSF to accelerate bone marrow regeneration and recovery of peripheral blood neutrophil counts. These studies indicated that higher doses of G-CSF were required to enhance the recovery of hematopoietic parameters to normal, suggesting that the role of G-CSF involved recruitment of earlier stem cells by some indirect mechanism involving cytokine cascades or, alternatively, reflecting the relative 
paucity of G-CSF receptors on primitive hematopoietic cells. Based upon our in vitro studies indicating that IL-1 upregulated the receptors for G-CSF and other CSF species on primitive hematopoietic stem cells that were resistant to irradiation and chemotherapy, we cultured bone marrow from mice treated with 5FU for $24 \mathrm{~h}$ with IL-1 prior to autologous transplantation in lethally irradiated mice. Following transplantation, recipients received IL-1 alone for 4 days, G-CSF alone for 21 days, or IL-1 plus G-CSF, and hematopoietic reconstitution was assessed. Preliminary studies indicated that in vitro pretreatment of bone marrow enhanced bone marrow reconstitution and accelerated recovery of peripheral neutrophil counts in mice that subsequently received IL-1, G-CSF, or a combination of IL-1 plus G-CSF in the post-transplant period. As measured by reconstitution of total stem cells and progenitor cells, hematopoietic recovery, and peripheral neutrophil counts, the most efficacious combination involved pretreatment of bone marrow in vitro with IL-1, followed by post-transplant treatment with a combination of IL-1 and G-CSF.

\section{Conclusion}

Numerous clinical trials are now underway using G-CSF and GM-CSF in iatrogenic myelosuppressive situations associated with cancer chemotherapy and irradiation therapy, and in conjunction with autologous and allogeneic bone marrow transplantation. Efficacy is also under study in congenital disorders of neutrophil production, and in myelodysplastic syndromes and myeloid leukemias. The initial promise of the CSFs and interleukins suggests that they may provide a major new therapeutic modality - but only if we can develop a deeper insight into their modes of action and interaction. The choice of the type of factor to be administered will be influenced by the particulars of the pathology being treat- ed, making it meaningless to generalize as to whether one factor is "better" than another. It is already clear that the timing, dose, and route of administration of hematopoietic growth factors are important variables and efficacy will have to be balanced against potential adverse side effects (which fortunately have not emerged as serious limitations in the case of G-CSF and GM-CSF trials). In addition, preclinical studies point to the value of combination biotherapy using two or more factors administered at the same time, or sequentially. Finally, there is a need to recognize that proliferative processes are self-limiting and physiological mechanisms probably exist to counteract the action of hematopoietic growth factors. Unraveling these issues will undoubtedly occupy the agenda of many future Wilsede Meetings.

\section{References}

1. Moore MAS (1988) The use of hematopoietic growth and differentiation factors for bone marrow stimulation. In: De Vita VT, Hellman S, Rosenberg SA (eds) Important advances in oncology 1988. Lippincott, Philadelphia, pp 31-54

2. Welte K, Platzer E, Lu L, Gabrilove JL, Levi E, Mertelsmann R, Moore MAS (1985) Purification and biochemical characterization of human pluripotent hematopoietic colony-stimulating factor. Proc Natl Acad Sci USA 82:1526-1530

3. Souza L, Boone TC, Gabrilove JL, Lai PH, Zsebo KM, Murdock DC, Chazin VR, Bruszewski J, Lu H, Chen KK, Barendt J, Platzer E, Moore MAS, Mertelsmann R, Welte K (1986) Recombinant human granulocyte colony-stimulating factor; effects on normal and leukemic cells. Science 232:61-65

4. Welte K, Bonilla MA, Gillio AP, Boone TC, Potter GK, Gabrilove JL, Moore MAS, O'Reilly J, Souza LM (1987) Recombinant human granulocyte colonystimulating factor: effects on hematopoiesis in normal and cyclophosphamidetreated primates. J Exp Med 1645:941 948

5. Moore MAS, Warren DJ (1987) Interleukin-1 and G-CSF synergism: in vivo 
stimulation of stem cell recovery and hematopoietic regeneration following 5-fluorouracil treatment in mice. Proc Natl Acad Sci USA 84:7134-7138

6. Gabrilove JL, Jakobowski A, Scher H, Sternberg C, Wong G, Grous J, Yagoda A, Fain K, Moore MAS, Clarkson B, Oettgen HF, Alton K, Welte K, Souza L (1988) Effect of granulocyte colony-stimulating factor on neutropenia and associated morbidity due to chemotherapy for transitional-cell carcinoma of the urothelium. $\mathrm{N}$ Engl J Med 318:1414-1422

7. Jakubowski AA, Souza L, Kelly F, Fain $\mathrm{K}$, Budman D, Clarkson B, Bonilla MA, Moore MAS, Gabrilove JL (1989) Effects of human granulocyte colony stimulating factor on a patient with idiopathic neutropenia. New Engl J Med 320:38-42

8. Hernandez Bronchud $\mathrm{MH}$, Scargge $\mathrm{JH}$, Thatcher N, Crowther D, Souza LM, Alton NK, Testa NG, Dexter TM (1987) Phase I/II study of recombinant human granulocyte colony-stimulating factor in patients receiving intensive chemotherapy for small cell lung cancer. $\mathrm{Br} \mathrm{J}$ Cancer 56: $809-813$

9. Taylor K, Spitzer G, Jagannath S, Dicke K, Vincent M, Souza L (1988) rhG-CSF hastens granulocyte recovery in Hodgkin's disease after high-dose chemotherapy and autologous bone marrow transplant. Exp Hematol 16:413 (abstr)

10. Lothrop CD Jr, Warren DJ, Souza LM, Jones JB, Moore MAS (1988) Correction of canine cyclic hematopoiesis with recombinant human granulocyte colony stimulating factor. Blood 72:1324-1328

11. Bonilla MA, Gillio AP, Ruggiero M, Kernan NA, Brochstein JA, Fumagalli L, Bordignon $C$, Vincent $M$, Welte $K$, Souza LM, O'Reilly RJ (1988) Correction of neutropenia in patients with congenital agranulocytosis with recombinant human granulocyte colony stimulating factor in vivo. Exp Hematol 16:520 (abstr)

12. Oppenheim J, Kovacs E, Matsushima K, Durum SK (1986) There is more than one interleukin-1. Immunol Today 7:45-56

13. Lovhaug D, Pelus LM, Nordie EM, Boyum A, Moore MAS (1986) Monocyteconditioned medium and interleukin 1 in- duce granulocyte macrophage colony stimulating factor production in the adherent cell layer of murine bone marrow cultures. Exp Hematol 14:1037-1042

14. Bagby GC, Dinarello CA, Wallace $P$, Wagner C, Hefeneider S, McCall E (1986) Interleukin 1 stimulates granulocyte macrophage colony stimulating activity release by vascular endothelial cells. $J$ Clin Invest 78:1316-1320

15. Neta R, Oppenheim JJ (1988) Why should internists be interested in interleukin 1 ? Ann Intern Med 109:1-3

16. Moore MAS, Warren DJ, Souza L (1987) Synergistic interaction between interleukin-1 and CSFs in hematopoiesis. In: Gale RP, Golde DW (eds) Recent advances in leukemia and lymphoma: UCLA symposium on molecular and cellular biology. Liss, New York, pp 445458

17. Mochizuki DY, Eisenman JR, Conlon PJ, Larsen AD, Tushinski RJ (1987) Interleukin 1 regulated hematopoietic activity, a role previously ascribed to hemopoietin 1. Proc Natl Acad Sci USA 84:5627

18. Warren DJ, Moore MAS (1988) Synergism among interleukin 1, interleukin 3, and interleukin 5 in the production of eosinophils from primitive hemopoietic stem cells. J Immunol 140:94-99

19. Stanley ER, Bartocci A, Patinkin D, Rosendaal M, Bradley TR (1986) Regulation of very primitive multipotent hemopoietic cells by hemopoietin-1. Cell 45:667-674

20. Jubinsky PI, Stanley ER (1985) Purification of hemopoietin-1: a multilineage hemopoietic growth factor. Proc Natl Acad Sci USA 82:2764-2767

21. Gabrilove J, Welte K, Harris P, Platzer E, Lu L, Levi E, Mertelsmann R, Moore MAS (1986) Pluripoietin alpha: a second human hematopoietic colony-stimulating factor produced by the human bladder carcinoma cell line 5637. Proc Natl Acad Sci USA 83: 2478-2482

22. Moore MAS, Welte $K$, Gabrilove JL, Souza LM (1986) In vivo action of recombinant human G-CSF on chemotherapy or radiation myelosuppressed mice. Blood 68 [Suppl 1]: 173 a (abstr) 